\title{
Del padecimiento a la diversidad: un camino hermenéutico
}

From complaint to diversity: a hermeneutic way

\section{Resumen}

El presente artículo pretende analizar y cuestionar las últimas tendencias paradigmáticas en torno a la "discapacidad" mediante un enfoque hermenéutico. Se propone un repaso histórico que determine el devenir de los grandes pensamientos surgidos acerca de este concepto. Posteriormente se profundiza en las teorías coexistentes dominantes y transgresoras que posibilitan nuevos modelos y paradigmas. Por último, se reflexiona sobre el estado actual del debate. ¿Hemos cambiado tanto?

\section{Palabras clave}

Discapacidad, diversidad funcional, paradigma, revisión bibliográfica, pensamiento crítico.

\section{Abstract}

This essay is intended to analyze and question the last paradigmatic tendencies about disability, by means of a hermeneutic perspective. A historical review is proposed in order to ascertain the development of the great statements, which have emerged from this notion. Subsequently, the composition delves into main, coexistent, and innovative prototypes and paradigms. Finally, it concludes with a reflection about the current state of the debate. Have we changed so much?

\section{Keywords}

Disability, functional diversity, paradigm, literature review, critical thinking.

\section{Gabriel Jiménez Pérez <elsacodmyg@gmail.com> \\ Universidad Pablo de Olavide \\ $\mathbf{M}^{\mathrm{a}}$ de las Mercedes Serrato Calero}

Universidad Pablo de Olavide

Para citar:

Jiménez Pérez, G. y Serrato Calero, M. M. (2OI4): "Del padecimiento a la diversidad: Un camino hermenéutico", Revista Española de Discapacidad, 2 (2): I85-206.

$<$ http://dx.doi.org/I0.5569/23405104.02.02.IO>

Fecha de recepción: I 5-09-20I4 Fecha de aceptación: 25-II-20I4 


\section{Introducción ${ }^{1}$}

En un momento de índole estructural cambiante en donde se habla de crisis por doquier, las optimistas vertientes la traducen como oportunidad -obviando su peligroso yang-22. Se nos suele presentar la realidad con dos caras, mas ¿cuál de ellas se califica como buena y cuál como mala? ¿Quién pierde con esta crisis y quién gana?

Ante una realidad partida en dos, se intentará aportar elementos suficientes para reflexionar acerca de los cimientos que sostienen una realidad llena de ficciones a la que llamaremos juego simbólico: a más polaridad, más desigualdad. El recorrido metodológico se ampara en la creencia de que "la raíz" del asunto provoca el sentido del producto. Y, para no caer en lo mismo que se pretende dudar y cambiar, hemos optado por un análisis hermenéutico: "Las ciencias sociales conciben su mundo desde la variabilidad inherente de la naturaleza humana sometida a las tensiones y subjetividades propias de la construcción social de la realidad" (Morán, 2006:283-284).

Hablamos de una manera de hacer ciencia crítica sin caer en lo que critica. "En el caso de las deducciones lógicas existe una regla de la que, dado un caso, se infiere un resultado" (...) En el caso de la inducción, dado un caso y un resultado, de ellos se infiere la regla (...) En el caso de la abducción, hay inferencia de un caso a partir de una regla y de un resultado" (Eco, I985).

No proponemos traducir ni concluir un proceso sino abrir nuevos pensamientos: transducir: "La inducción es el dominio de la generalidad, la deducción es el dominio de la universalidad, la transducción es el dominio de la singularidad" (Ibáñez, I985).

I. Agradecimiento especial a la Prof ${ }^{\text {a }}$ Antonia Corona Aguilar y a la Dra Rosa $M^{a}$ Díaz Jiménez. Sin ellas, quizás, no hubiera sido posible.

2. La palabra crisis en japonés (危機=kiki) está compuesta por los caracteres 危=“peligro" y 機= “oportunidad”, por lo que conforman una dicotomía como los complementarios taoístas yin y yang.
En este sentido, en una tendente sociedad posmoderna de anclaje neoliberal, surge un proceso que aboga por la particularidad, como lo es la "diversidad funcional" (Palacios y Romañach, 2006). Por ello, desde un intento de enfrentar posibles perversiones desde el sistema, y partiendo de una base en la que "los individuos sociales son relaciones y su conocimiento implica (como relación, a su vez, social) una perturbación de su proceso propio" (Ferreira, 2009:19), proponemos este enfoque para cuestionar el momento del concepto denominado generalmente como "discapacidad".

Para ello, ofreceremos un recorrido histórico en donde se muestren los espacios, protagonistas y antihéroes que jugaron este papel diverso, para así mostrar una herencia sociocultural y política que será traída al hoy para actualizar y, valga la paradoja, discapacitar a quien discapacita: "El punto de vista define el objeto (...) la mirada inscribe lo real en una red significante" (Almeida et al., 2010:37).

\section{De ayer a hoy: una historia paradigmática}

Se calla y Milada dice: - No tiene sentido que les cuentes todo eso. Hasta hace bien poco la gente se peleaba por probar quién había padecido más en el antiguo régimen. Sí, todo el mundo quería ser reconocido como víctima. Por suerte esa carrera por saber quién ha padecido más ya se ha acabado. Hoy la gente se jacta de tener éxito, no de padecer. Si la gente está dispuesta ahora a respetarte no es porque tu vida haya sido difícil, sino porque te ve al lado de un hombre rico-.

La Ignorancia (Kundera, 2000:46)

Es frecuente e incluso necesario, entre quienes estudian e investigan el ámbito de la discapacidad, vertebrarse en una común 
aceptación (científica) y referencia (heurística), denominado paradigma (Kuhn, 2002), al cual recurriremos en aras de situar los períodos y conflictos descritos como guía del presente texto. A su vez, nos fijaremos en la vertiente pragmática, los modelos, los cuales dan coherencia y uniformidad a una práctica en un muestrario de situaciones (Payne, I995: 80).

Es importante tener en cuenta que los paradigmas o modelos no se organizan en compartimentos estancos. No finaliza uno y comienza otro, no hay un momento clave en que se destierra una ideología o pensamiento y se adopta un nuevo esquema mental. De hecho, esta coexistencia suele generar conflictos y confrontaciones (Aguado, I993: 25; Díaz Jiménez, 2003; Egea y Sarabia, 2004: 22).

Delimitados los conceptos del análisis, abordaremos la fragmentación paradigmática. Es habitual que quienes trabajan sobre paradigmas los agrupen en tres bloques diferenciados, como por ejemplo es el caso de Jiménez y Huete (2010:138), quienes siguiendo a varios autores, distinguen entre: "Paradigma tradicional, del sometimiento o de la marginación", seguido del "Paradigma médico o de la rehabilitación” y concluyendo con el "Paradigma Social, de la autonomía personal o de la vida independiente".

Nuestro punto de partida es que no es la conciencia humana la que determina su copulativo natural o artificial ser, estar o parecer -igual o diferente-, sino, por el contrario, el ser social es lo que determina su conciencia (Marx, I980). Intentaremos proyectar aquí la manera en que una superestructura puede determinar su infraestructura desigualitaria con la cultura como medio (Oliver, I 994:I3; 2008:299-3 I4), con un "Dios" como todo, sin nada para muchos. Si algo es seguro es que pecaremos de etnocéntricos al partir desde la cultura en la que estamos inmersos y, desde ella, no desde la sumisión y sí desde la subversión, pretenderemos defender "nuestra historia".

El abanico del "principio de los tiempos" es muy amplio. Siempre se ha intentado explicar nuestro presente con el lastre del pasado ${ }^{3}$, nuestros orígenes, con más o menos suerte y más o menos fantasía. Si algo es coincidente en cualquier explicación mítica o mística son dos grandes paralelismos entre sí dignos de mención: provenimos de un primigenio desorden; $y$, segundo, desde el primer momento se sugiere la existencia dicotómica (Corbett, I99I, citado en Fulcher, 1998: 194) y contrapuesta (Aguado, I993: 25) del Bien/Mal, Dios/Demonio, Titán/ Monstruo, Hermoso/Funesto, Animal/Humano, Normal/Raro, etc.

Nos remontamos a un comienzo, un recorrido y un futuro marcado por una concepción tan antigua como latente. La diferencia de los diferentes ha sido tratada y entendida de formas diversas a lo largo de la historia. Siempre en oposición hacia una minoría (Barton, I998: 62), destacan los infanticidios cometidos contra niños deformes en épocas arcaicas (Tooley, 1983), el extravagante gusto de reyes y emperadores por divertidísimos bufones 4 (Douglas, I99I; Shakespeare, I994), las persecuciones eclesiásticas contra embrujados (Scheerenberger, I984:45), las torturas morales y físicas (Simon, I984), etc. Podemos observar todo un mundo de ideas, prejuicios y juicios, concepciones religiosas, vericuetos legales, paradigmas teóricos y modelos que intentan justificar o explicar, con más o menos suerte, la interacción de estas personas en un mundo que los recibió de formas diversas pero siempre desiguales (Scheerenberger, I984; Puig de la Bellacasa, I990; Casado, I99I; Aguado, I993; Barnes, I998; Díaz Jiménez, 2003; Egea y Sarabia, 2004).

Previamente al diseño de diferentes tratamientos curativos (primero benéficos, luego médicos) aplicados a quienes manifestaban alguna anomalía física o psíquica, el remedio fue singularmente genérico: el apartamiento, la represión y supresión e incluso la sátiras ${ }^{5}$.

3. "Está ampliamente aceptado que fueron los antiguos griegos quienes pusieron los cimientos de la «civilización» occidental" (Barnes, I998: 59-76).

4. Claro ejemplo de esto podemos observarlo en el cuadro

"Las Meninas" ( 1635 ) de Diego de Silva y Velázquez.

5. Un ejemplo puede ser el manual de cómo tratar a los ciegos “¡Así no! Así sí” que ilustró Forges con ONCE. 
Pasiva y animistamente la diferencia humana fue expandida desde los persas, persistiendo en la actualidad de maneras sutiles varias (Scheerenberger, I984; Freud, I988; Aguado, I993:26: 37; Egea y Sarabia, 200I: I7; Díaz Jiménez, 2003; Palacios, 2008) ${ }^{6}$. Parecía "imposible que en medio de este temporal pudiera surgir una nueva forma de concebir la vida, pero con sus virtudes y sus defectos, surgió" (Palacios, 2008).

Podemos decir que en un contexto en el que dominan las concepciones negativo-pasivas de la demonología, se instauran unas instituciones y unas prácticas plenamente activo-optimistas (Aguado, I993: 85; Palacios, 2008: 78). Para llegar a las versiones Coniecturalem artem esse medicinam $^{7}$ de Celso $^{8}$ o al Hipocrático ${ }^{9}$ primum non nocere ${ }^{I 0}$, y sin restar importancia a sus demás trasgresores (desde Galeno ${ }^{\text {II }}$ y Sorano de Éfeso $^{\text {I2 }}$, pasando por Averroes o Maimónides ${ }^{13}$, hasta las de "San" Luis IX ${ }^{14}$ ) debemos delimitar un punto de inflexión en términos significativos de cambio, siendo imperativo quedarse con el pensamiento homocéntrico. Con él no se desterró a Dios, no era ni imaginable tal cosa, pero en cierto modo cambió su lugar dentro de la ecuación y con menos pena que gloria apareció el Humanismo.

6. "Pocas etapas en la historia de la humanidad más descorazonadoras y tristes que la fanática, aunque dinámica, Edad Media". Extracto de Evolución histórica del concepto de discapacitado ante la sociedad de ASCLEPIO, Vol. XVII, I965. 7. "La medicina es el arte de suponer".

8. Enciclopedista romano del siglo I d. c. que abordó extensamente la disciplina médica en su obra "Tratado de Medicina".

9. Es considerado por muchos autores padre de la Medicina y la psiquiatría clínica.

Io. "Primero no hacer daño".

II. Junto con Hipócrates, trató de curar la epilepsia, a la que consideraba un problema psicológico más que metafísico (Thomas, I982).

I 2. Es interesante destacar que: "En la segunda centuria d.C., este médico griego asentado en Roma, padre de la ginecología y la pediatría, en su propio hospital atiende enfermos mentales y deficientes, probablemente. Sus tratamientos incluyen reposo, lectura y participación en representaciones teatrales" (Aguado, I993: 52).

I3. Destacados de la tradición árabe (Scheerenberger, I984).

I4. Se hace referencia a él en la página 468 de "Historia de las Cruzadas" Michaud (I8I5).
Comenzamos a abandonar la Edad Media, una época sombría que temía tanto la diferencia y la anormalidad que sólo necesitó la chispa del Santo Oficio para que prendieran las acusaciones de brujería, posesión demoniaca y tantas otras más. Todo, para bien y para mal, se ligaba a las fuerzas divinas que premiaban y, sobre todo, castigaban. Parece ser que la reforma protestante no trajo mayor fortuna a estas personas pues esta aprensión no iba a ser una exclusiva del catolicismo (Aguado, I993:59-63).

Dentro de los nuevos pensamientos que pronto invitarían a pensar, deteniéndonos en uno de los escritos, y siguiendo con el halo de "vitalidad" y provocación, el más social, completo y enciclopédico (Matheeussen, I993:45) lo tenemos en el valenciano Juan Luis Vives ${ }^{5}$. Por un lado, "se afirmaba que la obligación del pobre y del desvalido era aceptar voluntaria y alegremente su indigencia y sus dolorosas privaciones” y, por otro, que "la pobreza se consideraba antisocial, peligrosa y reprochable, y por lo tanto existía obligación de eliminarla, o al menos de reducirla a sus mínimas proporciones" (Palacios, 2008:75-76). Este ápice generó permutaciones y perturbaciones dadoras de la posibilidad de cambio residente en el desdichado de cuerpo presente ${ }^{16}$ gracias al rico prestante, es decir, un primer paso hacia una especie de legitimidad utilitaria.

Se propone, pues, uno de los avances -en su tiempo y forma- de mayor magnitud por sus anodinas y convulsas pretensiones y dictados en el seno religioso y social, que afectaba a la mirada para con aquellas personas hasta entonces sin opciones para integrarse desde y en la sociedad. Entre la calle y el cobijo, el oficio y el desquicio (Barton I998: 44) y sin ocio ${ }^{17}$ que hiciera de alivio, oscilaba la miseria del que fuera mendigo y ahora atendido o recluido.

I 5. Junto a su coetáneo Erasmo de Rotterdam, como con posteriores (René Descartes o Thomas Hobbes), algunas de sus obras fueron incluidas en el Index librorum probibitorum. I6. "La pereza y flojedad y no el defecto del cuerpo, es el motivo para decir que nada pueden. (...) Ninguno hay tan inválido que le falten del todo las fuerzas para hacer algo" (De subventione pauperum).

I7. El control era tal que "había que procurarles pequeños trabajos para evitar que descubrieran el placer del ocio" (Palacios, 2008). 
A su vez, llegados a este punto, podemos elucidar que las vicisitudes en el seno católico no fueron tan solo las presentes. Tanto a nivel discursivo como practicante (el Malleus Maleficarum ${ }^{18}$ de los monjes dominico alemanes Sprenger y Kraemer por el primero y el Decreto de Graciano $^{19}$ por lo segundo), se puso de manifiesto la original e incipiente duplicidad de direcciones ante la alteridad, pobreza y opresión generada en la Iglesia. En cuanto a las escisiones del catolicismo, con Lutero y Calvino como máximos exponentes, tampoco fueron más acogedoras (Laín Entralgo, I988; Scheerenberger, I984).

Probablemente por haber puesto el foco de atención en el hombre, en el ser humano, comienza a observarse más su padecimiento; lo cual es un salto más que reseñable para las mentalidades de la época, que denota por primera vez empatía. No es ya tanto un maldito como un enfermo, aunque en la mayor parte de los casos sus opciones de subsistencia pasan por la mendicidad, los asilos y la beneficencia católica. Las mutilaciones a causa de las frecuentes guerras, las enfermedades y epidemias debido a la insalubridad de la época, propician patologías sobrevenidas con explicaciones algo más razonables que la imposición de una deidad superior o el castigo divino. A causa de todo esto, se producen grandes avances médicos, quirúrgicos y ortopédicos. Se comienzan a practicar tratamientos muy novedosos e incluso comienza a ser más frecuente un rudimentario concepto de educación especial (Aguado, I993; Díaz Jiménez, 2003).

La utilidad social atisba futuros pensamientos ${ }^{20}$. El profesional de referencia no llevaría toga, sino bata, ya que su cura pasó de ser espiritual

I8. Merece reseña: "Cuando el paciente no encuentra alivio en los medicamentos, antes bien, empeora con ellos, la enfermedad es producto del demonio" (Scheerenberger, I984:45). I9. El Decreto de Graciano (II50) era aceptado extraoficialmente por la Iglesia y declaraba que toda persona concebida fuera del matrimonio nacía con el pecado original y era considerado "hijo de la ira"(Scheerenberger, I984:45).

20. Como, por ejemplo: "la esencia del mundo moderno: la soberanía de un sujeto prometeico que se relaciona con la naturaleza desde una actitud exclusivamente instrumental, utilitaria y productiva" (Benavides, 20I3: 32). a científicamente testada. Pese al desarrollo de múltiples remedios -atendiendo a si fuera meritorio de tal rédito (Barton, I998:37)-, la culpa seguía residiendo en el paciente que no tenía asegurada una solución para volver a ser una persona sana, eximiendo de responsabilidad al profesional que lo atiende (Barnes, I990, citado en Oliver, I998:37). Seguimos acentuando la individualidad del problema (Oliver, I 986:I6) desde un enfoque paternalista y discriminatorio (Oliver, I990; Aguado, I 993:65; I 53-I 54; Palacios, 2008:90; Benavides, 2013).

Es natural, por tanto, que la fe se traslade del juicio hierático al hipotético hipocrático. Todo se construye en base al déficit; se establece un modelo de individuo estándar y el detrimento del derecho comienza cuando un individuo se aleja del parámetro establecido. Como contrasentido, este modelo pretende ser universal e integrar a las personas con discapacidad, aunque por su propia naturaleza, solo admitirá a aquellas que se acercan a lo preestablecido como normal, las que sean capaces de "ocultar" o reducir sus limitaciones; normalizarse para integrarse.

En este sentido, destaca Aguado (I993: 76-79) el curioso caso español del Siglo de Oro, dónde, por una vez, podemos encontrar ejemplos menos negativos que en el resto del mundo occidental, de cierto adelanto en cuanto a visibilización de la diferencia. Destacan quienes poseen alguna discapacidad sensorial y, sobre todo, física. La literatura y la pintura están plagadas de representaciones de lo diferente. Un personaje real que ejemplifica esto podría ser el universal Miguel de Cervantes Saavedra, que a su vez posee una historia común a la de muchas personas con discapacidad de aquel tiempo, el mutilado de guerra: "el Manco de Lepanto". Era común la pérdida de algún miembro o sentido a causa de la defensa de la patria, el rey o la “verdadera religión”, y esto convertía a aquellos héroes en dignos tullidos, no exentos de ser bastante pobres también.

La alternativa a este modelo de "integración relativa” fue la institucionalización. Desde el siglo XVI al XIX comenzó a desarrollarse una 
nueva tecnología del control, la cual organizaba, dividía, vigilaba, imponía tareas, clasificaba, controlaba, etc. (Foucault, 2002: 5) Según este autor, la Ilustración no sólo implicó el avance de la ciencia o el pensamiento, sino que estos elementos a su vez espolearon el mecanismo para crear seres dóciles y útiles. De este modo se homogeneízan comportamientos, se controlan multiplicidades humanas. Este proceder se propaga en diversas instituciones: hospitales, ejércitos, talleres, sanatorios, etc. Por esto, concluye Foucault (2002) que el siglo XIX no solo nos regaló las libertades, también nos legó la sociedad disciplinaria. Descriptiva e incluso prescriptiva es esa frase de este autor francés que afirmaba que no era casual que un colegio, una cárcel y un psiquiátrico guardasen tanta semejanza arquitectónica entre sí.

En lo concerniente a la discapacidad, ya hemos comentado que esta opción, la del internamiento en instituciones, era la reservada a quienes no "podían integrarse" en la sociedad. Se trataba de un sistema paternalista, con pretensiones universales pero que privaba de derechos a estas personas (Benavides, 20I3). Y como una acción siempre implica una reacción, el paternalismo provocó la emancipación.

Como ya hemos visto en la etapa anterior, se produce la paradoja del impulso que los conflictos bélicos suponen para las personas con discapacidad. En este caso, las Guerras Mundiales implicaron un importante avance pues "esta situación estimuló el desarrollo científico de las prácticas de rehabilitación, así como el movimiento en defensa de los derechos de las minorías" (Brogna, 2009:I46). Es decir, comienza a tomarse conciencia de que no sólo es necesaria una rehabilitación médica para las personas con discapacidad, y con más o menos acierto surgen terapias psicológicas, farmacológicas y de otra índole para estas personas. Además empieza a cobrar fuerza el movimiento asociativo de familiares o afectados. La educación especial se populariza, así como el acceso al empleo, desarrollando mediante estas dos áreas no sólo el conocimiento académico sino también de habilidades personales y sociales (Díaz Jiménez, 2003, Egea y Sarabia, 2004:24-25).
Por otra parte, las primeras décadas del siglo $\mathrm{XX}$ nos brindan otro elemento decisivo para nuestra historia: la configuración del Estado de Bienestar. El sector público hace su aparición en la economía y muchos estados comienzan a considerar oportuno garantizar ciertos servicios mínimos a sus ciudadanos, lo que a su vez repercute positivamente en la producción y el crecimiento económico (Salazar, 2005:I 27). En siglos anteriores, los estados habían procurado mediante leyes y disposiciones benéficas ciertos auxilios a los colectivos más desfavorecidos, pero es en este punto cuando el Estado de Bienestar comienza a consolidarse como piedra angular de la democracia y el crecimiento económico. Su “consolidación” llega tras la crisis de los años treinta y, sobre todo, tras la Segunda Guerra Mundial, cuando se afianzan sus dos objetivos básicos: el pleno empleo y el crecimiento económico, unificando a la vez algo que parecía imposible, la democracia y la libertad económica, logrando así el sistema capitalista gran estabilidad. Las ramificaciones de esta concepción serán variadas en función del sistema político y sobre todo económico que impere en cada país, pero, con mayor o menor presencia, comienzan a aparecer conceptos como la universalidad de los servicios sociales, derechos sociales y la articulación de estos como la obligación de satisfacer las necesidades individuales de la ciudadanía (Salazar, 2005: I38-I39).

En cuanto a las personas con discapacidad, las cuales se veían en la delgada línea entre quedar "dentro o fuera" de la sociedad, fueron diversas las manifestaciones al respecto, si bien todas coincidían en varios puntos: la dificultad para adaptarse a las condiciones de la sociedad, dentro de sus aspiraciones e intereses, como por ejemplo, en el mercado laboral (Oliver, I998: 44). Una de las formas para poder mejorar su situación fue la unión de fuerza y discurso con referentes y lemas. Se debate entre la construcción (versión funcionalista de inevitable aparición) y creación (visión materialista que enfoca el origen en el capitalismo industrial) del problema, matices que pretenden ser mediados buscando el punto común de los mismos, reconociendo que las limitaciones se encuentran 
tanto en la propia discapacidad como en lo ajeno (Barnes, I998:60). Se acepta la existencia tanto de la situación como de la condición de discapacidad, en calidad de interacción como explicación etiológica (Pantano, 2009:79-92).

Un momento fundamental a nivel histórico, que puede ejemplificar varios aspectos a nivel práctico, se encuentra en la publicación por parte de la Organización Mundial de la Salud (OMS), en I980, de la Clasificación Internacional de Deficiencias, Discapacidades y Minusvalias (CIDDM). Si bien esta clasificación pretendía aportar un nuevo esquema, enfocado en la experiencia vivencial de la persona con déficit, su naturaleza era puramente medicalista, pues trataba la experiencia de la discapacidad siempre poniendo el énfasis en la enfermedad o la condición de salud en desventaja, frente a un ideal de salud y funcionalidad plenas (Egea y Sarabia, 200I:I6). Por este motivo, esta clasificación recibió críticas, además de episodios de disconformidad con las revisiones y traducciones (Egea y Sarabia, 200I:I7-I9). En 200 I finalmente aparece una nueva versión de esta clasificación, ahora con el nombre de Clasificación Internacional del Funcionamiento, de la Discapacidad y de la Salud (CIF). Simplemente el cambio de título ya nos da una impresión de lo que se pretende con el cambio: generar un abanico de concepciones, términos, escalas y rangos más sociales, que se alejen más de la deficiencia y se acerquen más a una vivencia real del sujeto (Egea y Sarabia, 200I:I9-2I). En definitiva, se observa el cambio de una concepción medicalista hacia una más "social".

Y así, poco a poco, se fueron abriendo las agendas políticas a temas que no se habían planteado y la sociedad, su mente, construida, creada, condicionada y situada en un entramado que parecía dar una nueva paradoxa, o paradogma, mejor digamos paradigma. Bajo este enfoque entenderemos que la primera etapa está teñida como tradicional (Puig de la Bellacasa, I990) y denominada como modelo de prescindencia (Palacios, 2008:37-66), aludiendo a los elementos míticos (los castigos divinos) relacionando lo que se sale de la "normalidad" establecida con algo no deseable que se debe intentar suprimir o al menos ocultar. A su vez, existen dos submodelos, el eugenésico y el de marginación (Palacios, 2008:30); de este modo se genera una colectividad de personas aisladas, apartadas de la vida comunitaria que vivirán entre la invisibilidad y el rechazo (Casado, I99I; Díaz Jiménez, 2003). Suele situarse esta delimitación conceptual en un periodo histórico comprendido entre la Prehistoria y la Edad Media.

El segundo paradigma, denominado como paternalista a nivel jurídico (Benavides, 2013; Puig de la Bellacasa, I990; Palacios, 2008), despierta cierta controversia a la hora de su situación histórica. Si bien por cronología debe ir a continuación del anterior, esto es, desde el Renacimiento hasta alcanzar casi la mitad del siglo XX, no son pocos quienes consideran que es precisamente esa mitad del pasado siglo donde debemos ubicarlo. Para nosotros es tan significativo el hecho de que "el maldito" pase a ser "el enfermo" que optamos por la primera delimitación, coincidiendo con el paso del pensamiento teocéntrico al homocéntrico. Las principales características distintivas son la medicalización y las terapias (relativizadas éstas en el contexto de la época y la institucionalización. Persiste el carácter benéfico, asistencialista e invisibilizador, aunque empezamos a encontrar figuras más o menos públicas con discapacidades físicas y sensoriales, en parte a causa de las mutilaciones provocadas por las guerras (Aguado, I993; 76-79).

El último de ellos, paradigma social, de la autonomía personal o de la vida independiente (Jiménez y Huete, 20I0:138), comprende desde el siglo XX hasta nuestros días. El énfasis de este cambio está en el hecho de que ya no se trata de ser una persona maldita o enferma, sino en la reivindicación de ser sujeto de pleno derecho. Esta evolución conceptual parte de una concepción social, entendiendo ésta desde la más básica semántica; es decir, ya no son las creencias condenatorias o los médicos y las instituciones quienes deciden, ordenan y etiquetan, es esa parte de la sociedad considerada diferente y sus familiares quienes se 
plantean cómo quieren organizar su existencia en todos los ámbitos de ésta (Díaz Jiménez, 2003). El paradigma social implicará un cambio de mentalidad mayor aún que el que se había hecho con las otras dos concepciones. La sociedad es la que pone barreras, no el destino o la biología, y estas personas reivindican un espacio que tenga la capacidad real de recibir a todos los individuos.

Una vez examinado a grosso modo el desarrollo histórico y paradigmático, nos preguntaremos: ¿Cuáles son las nuevas tendencias? ¿Dónde nos situamos en este momento? ¿Hacia dónde nos dirigimos? ¿Hemos logrado llegar a esa alternativa soñada? ¿Es posible seguir respondiendo? ¿Nos falta alguna pregunta?

3. Del hoy a la postmodernidad: un juego simbólico

Partiremos de la base de que cuando se narra, describe y cristaliza una teoría, un discurso o una historia, la representación, raciocinio y posicionamiento que se hace de ellos son supuestos, imaginarios y ficticios. No existe una única subjetividad que versione unilateralmente lo objetivado. Cada cual tendrá su objeción subjetiva. Por ello, proponemos a continuación "una aproximación crítica a la realidad social, que constituye un axioma para la imaginación sociológica" (Barton, I998:19). Pese a que nuestro conocimiento sobre lo que nos rodea será "siempre provisional e incompleto", apostamos por "no ser un empeño intelectual neutral e indiferente” (Giddens, I997).

Cada lectura comprenderá e interpretará nuestros argumentos de forma particular y, por ende, igual de subjetiva que otra. ¿O no? Ciertas ficciones perviven a lo largo de los siglos, y otras desfallecen en el camino; motivo, entre tantos otros, que determina el paradero actual. ¿Hay elementos, reglas o estructuras más relativas que otras? ¿Cuáles son? ¿Por qué? ¿Para qué? ¿Cómo? Y, sobre todo, ¿qué se dice desde la investigación y pensamiento crítico por ello? Para acercarnos a tales respuestas necesitamos aproximarnos a un ejercicio de abstracción que primero empiece en la teoría y más tarde en la práctica: la hermenéutica.

Propondremos tres bloques en los que radicaremos nuestra tesis. El primero será el del último desplazamiento de la noción de reglas del juego, nuestra "meta-ficción" ${ }^{21}$, para poder razonar la lógica del sistema-juego que nos rodea en nombre de la libertad individual. Por reglas entenderemos las variables que determinan el funcionamiento de la estructura social que nos estructura y que pasó de ser una concepción tradicional de verdad-realidad, articulación, construcción, modulación y verificación transcendental-religiosa a una técnica semiótico-científica que, en estos momentos, cual metamorfosis, se asienta como “credo neoliberal” (Ferreira y García Martínez, 20I4:9). Éste será el primer nivel de análisis, el reglamento común a la sociedad occidental ${ }^{22}$.

El segundo operará en torno a la discapacitación y con formación de las personas jugadoras "con discapacidad”, cuestión de reflexión, por la que abogamos, acerca de su etiología, por sus intolerables consecuencias.

Por último, se propondrá converger entre ambos niveles creando un tercero: la contingente puesta en juego en los equipos del paradigma social donde se formularán diversas "estrategias" que fueron desarrollándose para ganar y que ayudarán a reflexionar sobre sus logros y metas por conseguir.

2r. "La idea de una ciencia neutra es una ficción, y es una ficción interesada, que permite considerar científica una visión neutralizada y eufemística (y por lo tanto particularmente eficaz simbólicamente porque es particularmente desconocible) de la representación dominante del mundo social" (Bourdieu, 2008: 47, en Ferreira, 2010: 46).

22. Barnes (20IO) señala las diferencias a escala global que supone la discapacidad según las tradiciones alternativas a la Occidental. Lo referenciamos, y hacemos hincapié en tal matiz, ya que hay que partir de tal cerco para poder adaptar el discurso propuesto. 


\subsection{Reglas}

Hablamos de una nueva fe (Žižek, I998) “un nuevo despotismo que se cernía, silencioso, sobre el Mundo Moderno" (Béjar, I987:69). De la espiritualidad cristiana al pacto humanista de cohesionante conservadurismo se dio el salto al vacío del tejido social en base a las reglas del juego capitalista (Alemán, 2004) invocando una ideologización de lo público en detrimento propio en cuanto a espacio de relaciones sociales (Sennett, 20II).

Se produce así una "sacrosanta libertad individual” (García Manzano, 20 Iob: 244) que confunde y relaciona libertad individual con democracia, "fenómeno propio de los nuevos tiempos que lleva a un particular desinterés y eventual abandono de los asuntos públicos" reforzado con la idea de que hay "lides políticas (a quien) bien podían cederse la organización de la comunidad y dedicarse plenamente a sus quehaceres privados". "El Estado invadiría, con el tiempo, una esfera pública desierta" (Béjar, ı987:69) que muestra la "confianza" en el sistema "que los representa" (Hardt y Negri, 2004) y convierte en ciudadanos de bien (Ferreira y García Martínez, 20I4:9).

En este sentido, podríamos decir que existe una plena participación ciudadana en el sistema de la manera que a éste le interesa y hace que le interese a sus componentes. Es la paradoja de hablar de la sociedad individualista. La descomposición es sencilla: "un conjunto de reglas, una ideología para justificarlas, y una conciencia en el individuo que le haga esforzarse por cumplirlas" (Robbins, I964:I 8; citado en Montoro, I985:82 23. Se revierte así la culpa estructural por la individual: quien logra el éxito o fracasa es uno mismo.

"Las ilusiones económicas y políticas de estos últimos cuarenta años caen una tras otra" (Lazzarato, 20I3). El Bienestar Social resultó ser un señuelo: "las políticas keynesianas pusieron coto a la ficción de un mercado autorregulado" que llevó “a una nueva crisis económica”,

23. Citado a su vez en Ferreira (2012:5). resucitando "el ideario liberal, modificado con ingredientes nuevos, que podemos rastrear tanto en el ordoliberalismo alemán como en la Teoría del Capital Humano estadounidense” (Ferreira, 20I3b:8) -en España tendido a llamar emprendimiento-. Una ciudadanía en busca de una autorrealización basada en la esperanza del sueño americano, "imbuida de una cultura narcisista que preconiza la práctica universal del egoísmo" (Lasch ,I979)²4. Una ciudadanía que utiliza el arma de la ironía -como el juego con sus reglas- pero cuya mímesis no es por rebeldía sino por desapego (Lipovetsky, 2000) de aspirar libremente a la sarcástica realidad de la supervivencia individual diaria.

"La sociedad de consumo, que había transitado hacia una sociedad consumista, endeudando a muchas familias por la expansión del crédito, tocó a su fin" (Ferreira y García Martínez, 20I4: 7), polarizando (Castells, I996) y globalizando la mentalidad individual de la sociedad en su máximo exponente. Esto supone una "fisura" en la "que cada vez más gente tiene menos oportunidades objetivas de desarrollar un proyecto vital motivado por sus directrices: precarización laboral, desempleo, recortes... pobreza y hambre" (Ferreira y García Martínez, 2OI4: II).

Llegados a este punto, podemos dilucidar ${ }^{25}$ las consecuencias que provocan tales causas: ¿afectan estas reglas a su ciudadanía por igual? ¿Se consume una sociedad que reparte desigual? $¿$ ¿Son, realmente, las mismas reglas para todas las personas? ¿Afectan, igualmente, a las personas que están asociadas al "colectivo de la discapacidad"?

\subsection{Equipos}

Han quedado definidas las reglas estratégicas normalizantes cuya regulación procede de un saber experto que se asume en un sistema de

24. Citado en Béjar (1987).

25. "Y es aquí donde se genera la promesa, la illusio, de la salvación y, con ella, el valor simbólico del capital en juego: la legitimidad" (Ferreira, 2010: 50). 
dominación propiciado por el mismo. Esta dis-construcción de un capital simbólico que propone una competición social de mérito individual pretende representar lo que está en juego: "el conjunto de representaciones que motivan prioritariamente nuestras puestas en escena" (Ferreira, 2010:50). Se postulan así ficciones reglamentadas que permiten hablar, por tanto, del "discurso del poder, el cual al margen de la abstracción que supone nombrarlo de tal manera, tiene una presencia efectiva en nuestras existencias cotidianas” (Ibíd., 50).

Una vez delimitado el énfasis heterogéneoindividual, precisaremos sobre su interacción homogeneizante-social, es decir, cómo el equipamiento de reglas posibilita el reglamento de los equipos. Para ello, proponemos hablar de la sociedad no como un "conglomerado de culturas" sino más bien como "una constelación de diferentes grupos de poder”.

En este contexto "se hace necesario generar el consentimiento de los dominados a partir de su adscripción voluntaria a determinadas formas de interpretar la realidad que aseguren el mantenimiento del orden social" (Sumalla et al., 2013: I0). Falta un matiz que Gramsci estudiaría (Crehan, 2004; Rodríguez Prieto y Seco Martínez, 2007): “A estas interpretaciones ampliamente aceptadas como de sentido común, a estos sistemas de ideas y creencias a través de los cuales el Mundo es representado, y que establecen de hecho relaciones de dominación bajo el techo de un imaginario social compartido (...) en términos de consenso acrítico: (llamamos) hegemonía" (Sumalla et al., 2013: 10).

Para llevar a cabo tal estratagema, se antoja imprescindible la aplicación de "mecanismos de adoctrinamiento de naturaleza ideológica que operan mediante discursos de racionalidad; suministran buenas razones (...) que se sustentan en la apelación a dicotomías epistemológicas que son, a la par que tales, éticas y estéticas (nada más platónico: la Verdad, la Bondad y la Belleza van siempre de la mano)" (Ferreira, 20I3a: 9). En este sentido, "el objetivo es la homogeneización del pensamiento de los/as ciudadanos/as apelando a valores de carácter universalista y de naturaleza humanista" (20I3: 9) lo que nos hace recordar la coexistencia de matrices de pensamientos pasados y ulteriores.

Siguiendo tales principios, ¿cómo se materializa la asignación de equipos -concretamente el compuesto por personas "con discapacidad"-?

Situándonos dentro de una lógica de "de convicciones y de realidades, nutrida de juegos de poder" (Sossa, 20I I), la siguiente gran ficción será la de la genealogía y lógica binaria: bueno/ malo, derecha/izquierda, hombre/mujer, normal/ discapacitado (Canguilhen, I970; Rosato et al., 2009:I49). De esta manera, corremos el riesgo de naturalizar lo cotidiano (Bourdieu, I999; Ferrante y Ferreira, 20I0, 20II) y, por tanto, los procesos de exclusión desigual ${ }^{26}$ que a partir de ella operarían. Esto "implica echar abajo la posibilidad misma de la problemática puesta en acto, basada en el carácter social, histórico, relativo de la exclusión, y por tanto en su solución posible” (Karsz, 2004:I 88).

"La actitud de un grupo de atribuirse un puesto central con respecto a los otros grupos, en valorar positivamente sus propias realizaciones y particularismos, lleva a un comportamiento proyectivo frente a los exogrupos, que son interpretados a través del modo de pensar del endogrupo (Preiswerk y Perrot, I979:49). De nuevo, dos partes de una misma realidad, siempre una por encima de otra.

Se causa así una gran falacia: la inclusión excluyente o, de otra manera, la creación de las zonas invisibles como exterior constitutivo y distributivo (Barton, 2008:26) cuya expulsión no refiere a un afuera sino a una diferencia interna que sirve para circunscribir la esfera de los incluidos. A la hora de organizarnos, lo hacemos como "cultura de ángulos rectos" (Preiswerk y Perrot, I979).

26. "Debemos hablar de desigualdad por motivo de discapacidad. Como señala Procacci (I999: 37), el concepto de exclusión puede suponer una individualización de las situaciones, como aisladas dentro de la sociedad, situándolas en los márgenes de la misma” (Díaz Velázquez, 20I I:I60). 
En otras palabras, es posible que lo que denominamos discapacidad no sea más que una posible categoría pensada en base a la capacidad normativizada dentro de una jerarquía producida e inventada -tildada de natural-en términos de asimetría y desigualdad entre quien etiqueta y quien es etiquetado, es decir, entre un los tuyos y los demás. Lo normal y la otredad. Una manera un tanto anormal de "con-formar equipos": elijo los que no elegiría en mi equipo. "Todo valor tiene que ser ganado contra un antivalor (...), lo normal sólo cobra sentido y cabe ser entendido por contraposición a lo no normal, a lo a-normal” (Bachelard, I984).

$\mathrm{Y}$ es que, pese a que el principio de normalización (Nirje, I970; Mikkelsen, I975; Warnock, 1978) pretendía una integración lo más normal posible, a su vez provocaba una diferenciación entre quien era normal y quien no lo era. Hemos llegado, por tanto, a la ideología de la normalidad -y no la normalidad como ideología- (Zizek, I998; Palacios y Romañach, 2006; Palacios, 2008; Ferreira, 2008, 2010, 20II, 20I3; Rosato y Angelino, 2009).

Al fin y al cabo, todas las ficciones que hemos ido describiendo y conectando pueden sólo parecer eso, ideas y puntos de vista que merodean por nuestras percepciones. Dejando de lado el sentido común -efecto ideológico de la unión de cada ficción que bajó de teoría a práctica (Vain y Rosato, 2005:5I)-, a estas alturas debemos llegar a la consideración de que "un saber no produce conocimientos sobre el mundo, sino tan solo efectos de conocimiento" (Rosato et al., 2009:139).

"El conjunto de esquemas generativos a partir de los cuales los sujetos perciben el mundo y actúan en él” (Martín Criado, 2009) actúa “como un sistema de disposiciones durables y transferibles -estructuras estructuradas predispuestas a funcionar como estructuras estructurantes-”. Este hábitus (Bourdieu, I987; I99I; I999; Ferrante y Ferreira, 2007; Ferrante, 2008) trae consigo una de las claves para dar sentido al presente entramado: hablamos de la "hexis corporal simbólica”. Las ficciones pasan a ser una cualidad tangible que pone en praxis el equipo.
Es el cuerpo donde se encarnarán todas las ficciones enumeradas: la economía visceral de funcionamiento transversal; la política decidida a ser legitimadora del monopólico capital; nuestra lógica dominante, bipolar y binaria en base a la normalidad -o lo meritocrático, bello, ideal-. Es decir, nuestro cuerpo será quien represente, se estereotipe, se discapacite, se cambie, se compre, se venda como "ficción" cultural (Jensen, 200I: 63, en Pfeilstetter, 2010) y política (Preciado, 20I3) que logra imponerse como "alineación mental" (Foucault, 2002: I 16). El cuerpo como agente materializador (Butler, 2002: 19) de lo que hasta ahora era ciencia-ficción. Este "régimen sináptico del poder" no se halla "por debajo del cuerpo social, sino en él mismo". Podemos decir que el cuerpo es un contingente histórico producto del poder (Foucault, 2002), de ahí nuestra fijación.

De todas las interpretaciones que existen acerca de la influencia del cuerpo en torno a la creación de la discapacidad, la teoría de la invencibilidad es de las más transgresoras: el miedo a reconocer nuestra condición de paso en este mundo que justificamos, escondemos y utilizamos contra los que consideramos deficientes - de la cota de normalidad occidentalmente impuesta(Shakespeare, I994). Este "cuerpo defectuoso" (Hevey, I993) concede un holograma kármico para el creador y catártico para el ostentador (Fulcher, I998:I9I), fenómenos que a su vez inducen, entre otros daños colaterales, invisibilidad (Werneck, 2005).

El jugador/a del "equipo de las personas discapacitadas" acopla un rol de suplementariedad (Campbell, 2005), de polo negativo (Rodriguez Diaz y Ferreira, 20ı0:67) "mediante el cual la discapacidad (aunque aparentemente excluida y ausente) está presente en los discursos sobre la normalidad, la normalización y la humanidad" (Vico, 20I I:34). Su papel en el juego no es otro que el de la miscelánea negativa: un cuestionador-corroborador "implacable del orden al que ingresa desde tierras ignotas (cuya atribución de) falta de confiabilidad por lo errático de su rumbo (que representa) el punto de reunión de riesgos y temores que acompañan al espacio cognitivo, (es decir) el 
epítome del caos que el espacio social intenta empeñosamente (...) sustituir por el orden" (Vásquez Rocca, 2008).

Un jugador/a, por tanto, que haga de chivo expiatorio. El nudo gordiano se desata mediante un juego Girardiano en el que designa la ilusión unánime de una víctima culpable, producida por un contagio mimético, por la influencia espontánea que los miembros de una misma comunidad ejercen los unos sobre los otros" cuya víctima inocente es "el precio del apaciguamiento general” (Moreno Fernández, 2013:194-I95).

Esta monstruosa selección concluye en un equipamiento de "monstruos", logrando así que salga a la luz lo que se quiere ocultar y negar. Además, problematiza las categorías culturales, en tanto que muestra lo que la sociedad reprime (Cortés, I997:19). "Por ello, el monstruo deviene en el otro, diferente, proscrito, aberrante y anómalo, entendiendo que su existencia es rotundamente necesaria, ya que si no, las identidades y los cuerpos considerados normales no podrían ni definirse ni comprenderse” (Platero y Rosón, 2012:I30).

Así, la con-formación del "equipo de las personas con "discapacidad" es el resultado de "complejos procesos de naturalización o encubrimiento de la desigualdad estructural y la exclusión que esta produce" (Almeida et al., 2010:39). Eso sí, pese a que con más pena que gloria, durante la Historia, el equipo ha ido aunando alianzas -el conjunto feminista de Butler (I997; 2002) y Riddel (I998)-, conquistas, líderes y discursos en torno a sus injusticias, coherencias y reglas del juego. ¿Cuáles son las últimas tendencias?

\subsection{Estrategias}

Desde la aparición en escena de Ed Roberts al postulado encabezado por Javier Romañach (2006, 2008, 2009), hay apenas medio siglo. Lo que puede ser más difícil de cuantificar es cómo calificar la relevancia de su transgresión (Palacios, 2008:I09-II7) y su repercusión hasta el día de hoy (Dejong, I979; Shapiro, I994; García Alonso, 2003). Se produce un antes y un después ante la re-definición del concepto de independencia como el "control que una persona tiene sobre su propia vida” (Palacios, 2008:II3). Desde este momento, surgen diferentes estrategias de equipo que teorizan y practican en búsqueda del cambio del orden en el tablero bajo el argumentario de la vida independiente.

En un primer momento, los dos modelos estratégicos de referencia eran el funcionalistaestadounidense, que explicaba la construcción social del problema de la discapacidad como "un resultado inevitable de la evolución de la sociedad contemporánea”, y, como adversario, el sociopolítico-británico, que inspirado en las teorías materialistas de Marx y Engels sugiere que "la discapacidad y la dependencia son la creación social de un tipo particular de formación social; concretamente, el capitalismo industrial" (Barnes, I998: 60). El primero, heredero directo del paradigma médico-rehabilitador, deja que enfoquemos como eminentemente social y radical al segundo, que pone sobre la mesa la dualidad opresión-emancipación politizando la neutralizada cuestión del "equipo de personas con discapacidad", reclamando derechos de índole social (Hevey, I992; Morris, I993, citado en Abberley, I998: 92; Oliver, I986, I994; Darke, I994; Shakespeare, I996). Acontece la sublimación cuando, al dicotomizar por priorizar sobre lo sociocultural, dejan la lucha por el cuerpo, que pudo ser la bandera y quedó olvidado en la consulta médica. Esta derrota fue crucial además por su amnesia de lo sensorial, las emociones (Corker, I999, citado en Corker, 2008: I3 I) y la identidad (Hughes y Patterson, 2008:I2I).

Frente a este "sujeto sin cuerpo, carente de historia, influencia, significado y capacidad de acción” (Hughes y Patterson, 2008: I I I), surgen la esencialidad discursiva del postestructuralismo, encarnada desde el biopoder foucaultiano, y la corriente fenomenológica de la experiencia y dolor cinestésico del "cuerpo vivido" en pro de la de-construcción arque-típica de los discursos y prácticas del momento (Hughes y Patterson, 2008:II4-I2I). 
Sin un gran éxito ante sus espaldas, -ya que ante estos simulacros discursivos de significaciones no palpables (Shakespeare y Watson, I995), "lo real ya no es más que lo que solía ser, asumiendo la nostalgia el significado absoluto" (Baudrillard, I988: 67)-, surge lo que parecía, por su origen, uno de los referentes internacionales: el modelo integrador o biopsico-social (Díaz Velázquez, 2009: 88-90). Un modelo que se propone abarcar todos los campos discutidos en la cuestión discapacitante. La CIF pretende ser "su vehículo integrador de diferentes disciplinas y ciencias en todo el mundo (OMS, 200I)"; sin embargo, en esencia, "responde a una concepción aún médica o rehabilitadora de la discapacidad, pues a pesar de tener en cuenta los factores sociales, sigue centrando el núcleo de análisis y de intervención exclusivamente en el individuo, aunque asuman la incidencia de los factores contextuales en la emergencia y el desarrollo de la discapacidad" (Díaz Velázquez, 2009: 90).

Aunque también se desarrollan otros modelos de estrategia como el de la accesibilidad, relacionado con el concepto de "diseño para todos/as" (De Lorenzo, 2003: 62-63) o el de autonomía personal (Jiménez y Huete, 2010), el que se sitúa en alza -pese a seguir siendo una denominación de militancia- es el modelo de la diversidad.

Desde este modelo se reclama "la plena capacidad de elección como ser humano y ciudadano en plenitud de condiciones, en libertad, de modo individual, controlando todos y cada uno de los aspectos de su vida” (Maraña, 2004: 2I); confía en una autonomíaempoderamiento cuya individualidad sea moral antes que funcional, es decir, que pese a cualquier limitación o ayuda que sea necesaria, impere la autodeterminación del que pasa a ser clienteconsumidor (Iáñez, 2009:67-70); la dignidad -intrínseca/moral y extrínseca/jurídica- como el canto a la diversidad (Palacios y Romañach, 2006:190); defendiendo una Bioética que tenga en cuenta la Convención sobre los derechos de las personas con discapacidad de la ONU. Utilizarán para ello la expresión «mujeres $y$ hombres discriminados por su diversidad funcional» (ONU, 2006: 34), distanciando así a quienes padecen la desigualdad relacional dentro de la igualdad funcional.

Pese a que ofrece un nuevo imaginario que, en primera instancia, asume un papel cercano a $E l$ Dorado de las estrategias para el juego opresivo y discapacitante con el que reflexionamos aquí, "la bienintencionada voluntad de evitar un etiquetaje negativo ha hecho perder de vista al resto de la comunidad cultural que hasta ahora se había considerado eficaz designador de la diferencia” (García Manzano, 2010a).

Respecto de las dudas generadas por su figurada sencillez: ¿Tendrán todas las personas con diversidad funcional los recursos materiales y morales para ese cambio? "La experiencia humana es demasiado compleja y diversa para que quepa en cualquier explicación única” (López González, 2009: Io). "Otorgar a todos, pero de manera meramente formal, la humanidad significa excluir, con apariencias de humanismo, a todos aquellos que carecen de los medios para realizarla" (Bourdieu, I999:90).

Esta especie de "reducción al absurdo" es, paradójicamente, "tan amplia que pierde utilidad operativa" (Moscoso, 20I I) para aquellos afectados y, lo que es peor, "puede resultar atractiva para los responsables políticos que buscan soluciones baratas" (Soder, 1989).

Señala Riddel (I998:106) que "es asombroso cuánto se parecen a (...) las fórmulas de quienes abogan por el mercado libre, cuya misión durante décadas (...) se puede resumir como la de hacer que los gobiernos dejen de molestar a la gente". Sería como pasar del "paternalismo controlador que acosaba a las anteriores ideas del Estado de Bienestar” (ibíd., I998:120) a una especie de orfandad consentida.

"Este proceso podría ser mucho más efectivo si la mano muerta de cien años de caridad no les aplastara" (Oliver, I994: IO). Esta ilusoria desidia institucional (Moscoso, 20II) es compatible con la creación de nuevos términos que gusten más que el anterior: "Todos somos diversos funcionales”. Aunque ¿es esa la mejor solución? ¿Es lo políticamente correcto -en 
lo que se refiere al concepto- una práctica políticamente incorrecta -en lo que atañe al hecho-? Quizá negar el orden de los factores sí altere el producto.

Perder de vista la individualidad-diversidad de las personas puede ser resbaladizo, tanto como hacerlo con las fuerzas de ficción, económicas, culturales y sociales, que intervienen sobre nuestros cuerpos. "Deshacer los silencios y deconstruir las categorías, renegando incluso del término es peligroso. (...) Producen abstracciones que satisfacen a los intelectuales, pero que se pierden en el contacto con las discriminaciones y las desigualdades palpables" (Yates, I993: I69). Pese a que "es importante que los mitos negativos se cuestionen a través de la investigación”, (...) "podría no ser más que reemplazar un estereotipo por otro" (Hamsley, 2008:368). Aunque la última estrategia nos haga mirar hacia el futuro con optimismo, "el arrastre de las herencias culturales nos hace ver ese momento como algo lejanamente incierto" (Ferreira, 20I3a:I 5 ).

En resumidas cuentas, podemos decir que "de lo que aquí se trata o se sigue tratando no es de aprender a jugar para ganar, sino de aprender a jugar para reconocer, ensayar y pensar lo que realmente está en juego" (García Manzano, 2010b:247).

\section{El ayer en el mañana}

Tras analizar la historia, las concepciones paradigmáticas y detenernos en la disección del juego y sus reglas, nos encontramos con varios ejes; el capitalismo global en que vivimos, la sociedad conformada por lastres de toda índole y un tejido normativo con pretensiones universalistas. Está puesto el tablero para esas personas que, con su cuerpo físico o simbólico (Bourdieu, I986), intentan acceder a los espacios ciudadanos (Díaz Velázquez, 20I0:I I9).

En el apartado anterior hemos visto el modelo en ciernes, la apelación a la diversidad humana, la apuesta por considerar otras formas de funcionar: la Diversidad Funcional (Toboso y Guzmán, 20I0: 79). Con este enfoque se alude a una concepción prácticamente etnocultural (Moscoso, 20I I:78) o multicultural (Almeida et al., 20Iо:28), entendiendo que estas personas comparten una identidad cultural común que las identifica. A su vez nos encontramos ante un movimiento emancipatorio, casi revolucionario, que busca que sean las propias personas con discapacidad quienes se erijan como encargadas de defender y formular las reivindicaciones del colectivo (Ferreira, 20I0:63). Simultáneamente, este postulado que busca la redefinición nominal y social de una colectividad, aboga por una singularidad (Rodríguez Díaz y Ferreira, 20ı0a:305), pues la experiencia y vivencia individual de cada persona es la que originará una funcionalidad diversa (Toboso y Guzmán, 2010:79). En base a esta idea, se compara esta forma de diversidad humana con otras de orígenes distintos; étnico, artístico, ideológico, etc. Pero, afinando el concepto, se establece que la diversidad funcional es inherente al ser humano, pues toda persona aporta una manera distinta de funcionar. Que esta caracterización sea extensiva induce a pensar que entonces no existe un colectivo y que desde luego éste no necesita una protección especial (Toboso y Guzmán, 20I0:79-80). Advertimos la paradoja y se nos plantean diversos interrogantes: $¿$ ¿Hay entonces un colectivo o se aboga por la experiencia individual del sujeto? ¿Se necesita una protección social individual para cada persona o es una protección social generalizada como la que ya venía reivindicando el modelo social? Es más, si asumimos que dentro de la diversidad humana hay notables variantes a la hora de funcionar, ¿no estaremos volviendo al esquema de siempre? Es decir, un colectivo en el que se agrupan personas muy diferentes entre sí, unidas por una similitud que quienes teorizan han llamado de múltiples maneras; duelo, tragedia personal, etc. (Oliver, I998:48-50) O en la línea del paradigma social, sufren opresión por causas sociales (Abberley, 2008:37).

Sea como fuere, hay algo que lleva a pensar que al final siempre hablamos de lo mismo; aunque se intente renombrar o reenfocar, solo cambia la forma, no el fondo. Es peligroso reunir en una 
cesta, una bolsa (Almeida et al., 2010:32), un saco (Rodríguez Díaz y Ferreira, 20Iob:I 55 ), a las diversidades diversas, podemos no saber de qué hablamos cuando hablamos de diferencias (Almeida et al., 20I0:3 I). Y, por otra parte, en el ámbito concreto de la discapacidad, la diversidad funcional o como proceda llamarlo, esa conformación que ya existe en la actualidad, ese saco de deficiencias múltiples y variadas donde se agrupan personas con unas necesidades muy diferentes pero una misma etiqueta social, puede conformar un colectivo administrativo, pero será raro que genere una colectividad en que todos sus miembros se encuentren unidos por lazos de reconocimiento y solidaridad. La conformación de esta masa a veces resulta menos homogénea de lo que las teorías y las administraciones han desarrollado en sus discursos, ocultando diferencias de base que tienen significativa repercusión en el modus vivendi de los sujetos interesados en la cuestión, en parte condicionada por el hecho de padecer una patología de nacimiento o una adquirida (García Manzano, 20I0a:246). En el segundo caso se produce una particularidad en la experiencia vivencial, puesto que el sujeto ha pertenecido previamente a la parte normalizada de la sociedad (García Manzano, 20Ioa:247) y este destierro social origina una situación peculiar, cuanto menos. Por ejemplos como este, sí alcanzamos a entender la reivindicación de enfocar la discapacidad como una vivencia individual y singular de la persona propuesto por el modelo de la diversidad funcional, pero es también este punto el que vuelve a generarnos más interrogantes: ¿̇es real y plena la autodeterminación del colectivo? Es decir, dentro de la colectividad de diversos acreditados existen personas cuyas capacidades cognitivas no les permiten desarrollar una conciencia de su situación tal y como la sociedad y este grupo concreto la entiende (García Manzano, 20Ioa:247-248). ¿Qué proponen los movimientos autodeterministas de diversos funcionales para quienes no pueden reivindicar ni ejercer el derecho a la vida independiente? ¿Estamos segregando dentro de la segregación en base a sesgos cognitivos?

¿Y la sociedad que no pertenece a este sector? ¿Qué percibe? Responder a esto sería materia de otro trabajo mucho más extenso pero podemos obtener respuestas significativas basándonos en algunos elementos que la sociedad produce y consume, donde las personas con discapacidad aparecen de distintas formas. Los medios de comunicación, generadores y consumidores de discursos públicos nos permiten observar algunas percepciones sociales.

En el caso de la prensa escrita aún es frecuente encontrar una polarización a nivel de contenido, distinguiendo dos tipologías de relato diferenciadas: los héroes y heroínas, y quienes merecen compasión. Las historias de “superación personal”, basadas en hombres y mujeres excepcionales en su carrera profesional, sea ésta del tipo que sea, ocuparán reportajes o noticias extensas en las que no faltarán términos de admiración, valoraciones positivas, tratamiento de "historia ejemplificante" y un largo etcétera. Las noticias sobre injusticias o hechos negativos serán breves, paternalistas, compasivas, etc. (Fernández-Cid, 20IO:I IOI I2). De igual manera veremos reflejadas a las personas con discapacidad sin ser protagonistas de sus noticias, pasando a ser personajes sin voz, de los que se habla pero no hablan. Esto suele ser más frecuente en las informaciones del segundo tipo. En una apreciación inicial, podemos observar que dentro de la masa social con discapacidad, la cual no sabemos aún si la sociedad percibe como diversos funcionales, el sesgo no responde tanto a orígenes patológicos sino que la distinción se origina en otro punto.

La sociedad, constructora de espacios simbólicos (Bourdieu, I986), recompensa y premia el trabajo de aquellos que con su cuerpo físico, y también simbólico, hacen el esfuerzo de ocupar un lugar en ese espacio, por ponerse "a la altura de los demás” y, a la vez, por pretender cumplir las exigencias que en nuestra realidad establece el capitalismo (Ferreira, 2010:48-52). Estas piezas informativas que ensalzan valores de superación personal suelen pivotar sobre dos ejes, el drama y el logro. Para quienes ejercen el periodismo, es muy tentador en incontables ocasiones, dejarse llevar por el sensacionalismo, la tragedia que puede haber tras la situación de discapacidad o el relato dramático de 
cómo se llegó a ella, si fue provocada por un accidente y casos similares (Solves, 2OI 2:4445 ). Desarrollan lo que se ha denominado como "Síndrome Dickens". Se llama así a la tendencia que los periodistas sienten cuando quieren que el público empatice con la historia, destacando por encima del tema central aspectos dramáticos que a la vez se transforman en logros, generando un relato épico que transgrede lo periodístico y contribuye a la construcción mítica de un héroe (Rius, 20I2:I24-I3I). Este fenómeno no es exclusivo de las informaciones que involucran a personas con discapacidad, pero sí es uno de los colectivos donde más frecuente y fácilmente lo encontramos. De hecho, nos preguntamos si este síndrome también entra en juego cuando los relatos provienen de los propios organismos o entidades del colectivo de personas con discapacidad. En este caso nos referimos a varios ámbitos del mundo de la información; desde la producción de noticias hasta la publicidad ${ }^{27}$. Obviamente entendemos la necesidad de utilizar elementos positivos en todo lo que compone cierto ámbito público de la discapacidad. En este sentido, se viene trabajando desde hace tiempo en la búsqueda de un tratamiento adecuado de este colectivo en los medios de comunicación, desarrollando trabajos y guías que ofrezcan un marco referencial en cuanto a lenguaje o tratamiento de contenidos (Casado, 200I; Sánchez de Amo y Marqués, 2003; Fernández Iglesias, 2006). Pero no podemos olvidar que lo que se dice es tan importante como lo que se omite. El otro grupo de noticias donde las personas con discapacidad carecían de voz es tanto o más significativo a nivel conceptual. Para ellos no hay síndrome porque no hay logro; tienen que conformarse con la otra cara de la moneda. Y aún así, tomando las informaciones de carácter positivo, ¿son el reflejo de cambios sociales o del pensamiento colectivo? ¿Esa visión que destaca la discapacidad para construir el logro no estigmatiza (Goffman, 2003) aunque sea de forma "bienintencionada"?

27. Hay anuncios, como éste de Fundación ONCE, que ejemplifican esta tendencia: http://www.youtube.com/ watch?v=PsNBOC 9 brPos.
Pese a todo, a las distintas evoluciones que ya hemos visto, no en materia de ciencias de la información, sino en ámbitos macro, en contextos culturales, sociopolíticos, económicos, ¿hemos avanzado tanto como cabría esperar? ¿Hemos conseguido superar concepciones e ideas del pasado en torno al saco que aglutina a los que históricamente fueron diferentes? Ya hablamos en el apartado destinado al desarrollo histórico y conceptual de la coexistencia paradigmática, la advertencia de que los viejos pensamientos no han sido del todo desterrados, pues persisten en muchas ideas y prácticas actuales (Díaz Jiménez, 2003); tal vez camuflados, maquillados o reubicados en los nuevos esquemas, pero presentes en cualquier caso. Para muestra, un ejemplo. Ferreira (2010:46-47) habla de la búsqueda que el colectivo de personas con discapacidad hace para encontrar una sanción legitimadora por parte del discurso médico. Pero sentirse menos enfermo no lo es todo y hay un fuerte acento en la importancia de sentirse más aceptado socialmente. Pero Ferreira (2010:5I) tiene réplica a esto y afirma que esa aceptación, tanto a nivel familiar como social, sigue siendo una extensión de la deslegitimación médica: qué, quién y por qué aparece, pues es esta ciencia quien la ha originado, por lo que impera estar sano o parecer que se está poco enfermo, logrando un buen nivel de aceptación (Toboso y Guzmán, 2010:78) en los espacios simbólicos (Bourdieu, I986) que la sociedad ha construido. El arcaico modelo médico maquillado y revitalizado por el capitalismo actual.

El lastre que imponen los siglos parece igual de pesado que el de los viejos discursos camuflados en la cotidianidad actual. Existen nuevas formas de "exclusión aniquiladora" o "integración utilitaria" (Casado, I99I) que de manera sutil habitan en el pensamiento colectivo.

En los últimos veinte años hemos presenciado avances legislativos y normativos en materia de discapacidad, avances muy significativos pero que no han tenido tanta repercusión práctica (Ferreira, 2010:63) ni a nivel general, en la sociedad, ni a nivel más concreto, en el "saco" de los diferentes con certificado. Incluso 
contando con el reconocimiento de igualdad extensivo a toda la ciudadanía, este colectivo tiene unas condiciones sociales particulares que lo limita, es decir, lo excluye, de diferentes formas en la vida pública (Díaz Velázquez, 20IO:I32); esto es, las reglas del juego llegan a impedirles jugarlo plenamente.

¿El nuevo enfoque de diversidad funcional podrá luchar contra todo esto? El saco de personas diferentes sigue ahí, administrativamente constituido, baremado en base a los criterios de la CIF, aceptado por las personas, excluido por la sociedad. Cómo denominar a esta masa es importante pero se cae en el riesgo de que la retórica lleve al eufemismo (Almeida et al., 2010:30), más aún cuando la propuesta que hay tras el nombre aún no tiene una estructura consolidada, se apoya en pilares que en ocasiones no son sólidos y que en otras están demasiado arraigados en el sistema como para poder moverlos.

Hay personas -entre las que me cuento- que detestan los finales felices.

(Vladimir Nabokov Pnin)

\section{Referencias bibliográficas}

Abberley, P. (2008): "El concepto de opresión y el desarrollo de una teoría social de la discapacidad". En: Barton, L. (comp.): Superar las barreras de la discapacidad, Madrid: Morata: 34-50.

Abberley, P. (I998): “Trabajo, Utopía e insuficiencia”. En: Barton, L. (comp.): Discapacidad y Sociedad, Madrid: Morata: 77-96.

Aguado Díaz, A. L. (1993): Historia de las deficiencias, Valencia: Alfaplús.

Alemán, J. (2004): Derivas del discurso capitalista, Madrid: Miguel Gómez Ediciones.

Almeida, M. E. et al. (2010): "Nuevas retóricas para viejas prácticas. Repensando la idea de diversidad y su uso en la comprensión y abordaje de la discapacidad", Política y Sociedad, 47(I): 27-44.

Bachelard, G. (I984): La filosofía del no: ensayo de una filosofía del nuevo espíritu científico, Buenos Aires: Amorrortu.

Barnes, C. (2010): “Discapacidad, política y pobreza en el contexto del 'Mundo Mayoritario'”, Política y Sociedad, 47(I): II-25.
Barnes, C. (I998): "Las teorías de la discapacidad y los orígenes de la opresión de las personas discapacitadas en la sociedad occidental". En: Barton, L. (comp.): Discapacidad y sociedad, Madrid: Morata: 59-76.

Barton, L. (I998): “Sociología y Discapacidad: algunos temas nuevos”. En: Barton, L. (comp.): Discapacidad y Sociedad, Madrid: Morata: 19-33.

Baudrillard, J. (I988): America, London: Verso.

Béjar, H. (I987): “Autonomía y Dependencia: La tensión de la intimidad”, REIS, I (37): 69-90.

Benavides López, A. F. (20I3): “Modelos de capacidad jurídica: Una reflexión necesaria a la luz del Art. I 2 de la Convención Internacional de los Derechos de las Personas con Discapacidad", Tesis Doctoral, Director Rafael de Asís Roig Madrid: Instituto de Derechos Humanos Bartolomé de las Casas, Universidad Carlos III de Madrid.

Bourdieu, P. (I999): Meditaciones pascalianas, Barcelona: Anagrama.

Bourdieu, P. (I987): Cosas Dichas, Barcelona: Gedisa. 
Bourdieu, P. (I986): "Notas provisionales sobre la percepción social del cuerpo”. En: AlvarezUría, F. y Varela, J. (eds.): Materiales de sociología crítica, Madrid: La Piqueta: I83-I94.

Brogna, P. (2009): “La representación de la discapacidad: La vigencia del pasado en las estructuras sociales presentes”. En: Brogna, P.: Visiones y revisiones de la discapacidad, Argentina: Fondo de Cultura Económica.

Butler, J. (1997): Excitable Speech: a politics of the performative, Nueva York: Routledge.

Butler, J. (2002): Cuerpos que importan: Sobre los limites materiales y discursivos del sexo, Buenos Aires: Editorial Paidós.

Cachorro, G. (2008): “Cuerpo y subjetividad: Rasgos, configuraciones y proyecciones”, Jornadas de Cuerpo y Cultura de la UNLP.

Campbell, F. K. (2005): “Legislating Disability. Negative Ontology and the Government of legal identities”. En: Tremain, S. (ed.): Foucault and the Government of Disability, Ann Arbor: University of Michigan: I08-I33.

Canguilhen, G. (I970): Lo normal y lo patológico, Buenos Aires: Siglo XXI.

Casado, D. (200I): Comunicación social en discapacidad. Cuestiones éticas y de estilo, Madrid: Real Patronato sobre Discapacidad, Ministerio de Trabajo y Asuntos Sociales.

Casado, D. (I99I): Panorámica de la discapacidad, Barcelona: Intress.

Casado, D. y Egea, C. (2002): “Las estrategias para el cambio por inclusión de las personas con discapacidad", en Unidos con la Discapacidad, memoria del IV Congreso Internacional, México DF: 63-69.

Castells, M. (I996): "El cuarto mundo: capitalismo informacional, pobreza y exclusión social”. En: Castells, M.: La Era de la Información, I(3), Barcelona: Siglo XXI: 95-I98.

Corker, M. (2008): "Diferencias, funciones y bases ¿Son estos los límites de la representación teórica 'precisa' de las experiencias de las personas con discapacidad?”. En: Barton,
L. (comp.): Superar las barreras de la discapacidad, Madrid: Morata: I24-I4I.

Cortés, J. M. G. (I997): Orden y caos, Barcelona: Anagrama.

Crehan, K. (2004): Gramsci, cultura y antropología, Barcelona: Bellaterra.

De La Parra, M. A. (2002): El cuerpo de Chile, Santiago: Planeta.

Dejong, G. (I979): The Movement for Independent Living: Origins, Ideology and Implications for Disability Research, East Lansing: Michigan State University Press.

Díaz Jiménez, R. M. (2003): Personas con discapacidad. Una aproximación desde el trabajo social, Sevilla: Aconcagua Libros.

Díaz Velázquez, E. (20I I): "Estratificación y desigualdad por motivo de discapacidad", Intersticios, 5(I): I 57-I70.

Díaz Velázquez, E. (20I0) “Ciudadanía, identidad y exclusión social de las personas con discapacidad", Politica y Sociedad, 47(I): II5-I3I.

Díaz Velázquez, E. (2009): "Reflexiones epistemológicas para una sociología de la discapacidad", Intersticios, 3(2): 85-99.

Díaz, E. (2005): Postmodernidad, Bueno Aires: Biblos.

Douglas, M. (I99I): Pureza y Peligro. Análisis de los conceptos de contaminación y tabú, Madrid: Siglo XXI.

Egea, C. y Sarabia, A. (2004): "Visión y modelos conceptuales de la Discapacidad", Polibea, 73: 2I-37.

Egea, C. y Sarabia, A. (200I): "Clasificaciones de la OMS sobre discapacidad”, Boletín del Real Patronato sobre Discapacidad, 50: I 5-30.

Fernández Iglesias, J. L. (2006): Guía de estilo sobre discapacidad para profesionales de los medios de comunicación, Madrid: Real Patronato sobre Discapacidad, Ministerio de Trabajo y Asuntos Sociales.

Fernández-Cid, M. (20I0): "Medios de comunicación, conformación de imagen y construcción de sentido en relación a la 
discapacidad", Política y Sociedad, 47(I): I05-II3.

Ferrante, C. (2008): “Cuerpo, discapacidad y posición social: una aproximación indicativa al habitus de la discapacidad en Argentina", Intersticios, 2(I): I73-I 85 .

Ferrante C. y Ferreira M. A. V. (20IO): "El hábitus de la discapacidad. La experiencia corporal de la dominación en un contexto económico periférico", Política y Sociedad, 47(I): 85-I04.

Ferrante, C. y Ferreira, M. A. V. (2007): "Cuerpo y habitus: el marco estructural de la experiencia de la discapacidad", Revista Argentina de Sociología (en proceso de evaluación) (en línea). <http://www.um.es/ discatif/PROYECTO_DISCATIF/Documentos/ Ferrante_Ferreira.pdf $>$.

Ferreira, M. A. V. (2013a): "Cuerpo, Emociones y Crisis: Una Perversión <Terapéutica>”, Intersticios, 7(2): 6-I6.

Ferreira, M. A. V. (2013b): "El cuerpo-empresa de la (meta) (trans) (post) (hiper) modernidad", XI Congreso Español de Sociología, FES, Federación Española de Sociología, Madrid, IO-I 2 julio de 2013 (paper).

Ferreira, M. A. V. (20II): "Discapacidad, globalidad y educación: ¿una nueva 'política del cuerpo'?”, Revista Latinoamericana de Estudios sobre Cuerpos, Emociones y Sociedad, 2(6): 6-I9.

Ferreira, M. A. V. (20I0): "De la Minus-valía a la Diversidad Funcional: Un nuevo marco teóricometodológico", Política y Sociedad, 47(I): $45-65$.

Ferreira, M. A. V. (2009): "Lo social como proceso: la transductividad ontogenética de las prácticas sociales”, Nómadas. Revista Crítica de Ciencias Sociales y Jurídicas, 22(2): I 29-I47.

Ferreira, M. A. V. (2008): “La construcción social de la discapacidad: habitus, estereotipos y exclusión social", Nómadas. Revista Crítica de Ciencias Sociales y Jurídicas, I7(I): 22I-232.

Ferreira, M. A. V. (2007a): La vida antes del laboratorio. La construcción de los constructores de hechos científicos, Madrid: CIS.
Ferreira, M. A. V. (2007b): "Un nuevo concepto para la comprensión de la acción social: la transductividad creativa de las prácticas cotidianas", Intersticios, I(I): I 6.

Ferreira, M. A. V. (2004): “¿Mito o razón?: una bifurcación histórica cuya unidad resurge en la ciencia contemporánea”, Nómadas, ıо.

Ferreira, M. A. V. y García Martínez-Arrarás, J. (20I4): "Neoliberalismo y Modernidad: La crónica de un suicidio colectivo y las lecciones no aprendidas de la Modernidad", Intersticios, $8(\mathrm{I}):$ 5-I 8 .

Foucault, M. (2002): Vigilar y castigar: Nacimiento de la prisión, Buenos Aires: Siglo XXI.

Freud, S. (I988): El malestar de la cultura, Madrid: Alianza.

Fulcher, G. (I998): "Entre la normalización y la Utopía”. En: Barton, L. (comp.): Discapacidad y Sociedad, Madrid: Morata: I8I-204.

García Alonso, J. V. (Coord.) (2003): El movimiento de vida independiente. Experiencias Internacionales, Madrid: Fundación Luis Vives.

García Manzano, E. (2010a): “Marginalia”, Intersticios, $4(\mathrm{I}): 245^{-25} \mathrm{I}$.

García Manzano, E. (20Iob): "De la exclusión integrada a la integración excluyente", Interticios, 4(2): 239-250.

Gómez García, P. (I984): "Para criticar la Antropología Occidental: Etnocentrismo y nueva crítica de la Razón”, Gaceta de Antropología, 3.

Hardt, M. y Negri A. (2004): Multitud. Guerra y democracia en la era del imperio, Buenos Aires: Debate.

Hevey, D. (I993): “The tragedy principle: strategies for change in the representation of disabled people”. En: Swain, J.; Finkelstein, V.; French, S. \& Oliver, M. (eds.): Disabling Barriers: Enabling Enviroments, Londres: Sage.

Iáñez, D. A. (2009): Prisioneros del cuerpo. La construcción social de la diversidad funcional, A Coruña: Diversitas. 
Ibáñez, J. (I985): Del algoritmo al sujeto: perspectivas de la investigación social, Madrid: Siglo XXI.

Illich, I. (I980): “Alternativa al desarrollo", El viejo Topo, 44: 8.

Jiménez Lara, A. y Huete García, A. (2010): "Políticas públicas sobre discapacidad en España. Hacia una perspectiva basada en los Derechos", Política y Sociedad, 47(I): I37-I 52.

Karsz, S. (coord.) (2004): La exclusión: bordeando sus fronteras, Barcelona: Gedisa.

Kuhn, T. (2002): El Camino desde la Estructura. Ensayos Filosóficos 1970-I993, con una entrevista autobiográfica, Barcelona: Paidós.

Kundera, M. (2000): La Ignorancia, Barcelona: TusQuets.

Laín Entralgo, P. (1988): Historia de la medicina, Barcelona: Salvat.

Lazzarato, M. (2013): La fábrica del hombre endeudado: Ensayo sobre la condición neoliberal, Madrid: Amorrortu.

Lipovetsky, G. (2000): Era del vacío, Barcelona: Anagrama.

Llaguno, M. M. (2008): "La tiranía de la apariencia en la sociedad de las representaciones”, Revista Latina de Comunicación Social.

López González, M. (2009): Modelos teóricos e investigación en el ámbito de la discapacidad. Hacia la incorporación de la experiencia personal, Córdoba: Ciencias de la Educación, Universidad de Córdoba.

Mainetti, J. A. (I993): "Filosofía del vestido", Estudios bioéticos II, La Plata: Quirón.

Maraña, J. J. (2004): Vida independiente. Nuevos modelos organizativos, A Coruña: Asociación Iniciativas y Estudios Sociales.

Marx, K. (I980): Contribución a la crítica de la economía política, Madrid: Siglo XXI.

Matheeussen, C. (I993): "El humanismo de los Países Bajos y Juan Luis Vives”. En: Puig de la Bellacasa, R.: La discapacidad y la rehabilitación en Juan Luis Vives: Homo homini par, Madrid: Real Patronato de
Prevención y de Atención a Personas con Minusvalía: 28-45.

Michaud, M. (I 8 I 5): Historia de las Cruzadas, Barcelona: Librería Española.

Morán, J. M. (2006): Epistemología, Ciencia y Paradigma en Trabajo Social, Sevilla: Aconcagua Libros.

Moreno Fernández, A. (20I3): “Descripción y fases del mecanismo del Chivo Expiatorio en la teoría mimética de René Girard", Series Filosóficas, 32: 191-206.

Morris, D. (2005): La mujer desnuda. Un estudio del cuerpo femenino, Barcelona: Planeta.

Morris, J. (2008): “Lo personal y lo político. Una perspectiva feminista sobre la investigación de la discapacidad física". En: Barton, L. (comp.): Superar las barreras de la discapacidad, Madrid: Morata: 3I 5-326.

Moscoso Pérez, M. (20 I I): "La discapacidad como diversidad funcional: los límites del paradigma etnocultural como modelo de justicia social", DREIA Dilemata: Revista internacional de éticas Aplicadas, 7(3): 77-92.

Nirje, B. (I970): “The normalization Principle, Implications and Comments", Symposium on Normalization, Madrid.

Oliver, M. (2008): “¿Están cambiando las relaciones sociales de la producción investigadora?”. En: Barton, L. (comp.): Superar las barreras de la discapacidad, Madrid: Morata: 299-3 I4.

Oliver, M. (I998): “¿Una sociología de la discapacidad o una sociología discapacitada?”. En: Barton, L. (comp.): Discapacidad y Sociedad, Madrid: Morata: 34-58.

Oliver, M. (I994): “Capitalism, Disability and ideology: a materialist critique of the normalization principle”, Ponencia presentada en una conferencia internacional sobre normalización, en la Universidad de Ottawa, Canadá (paper).

Oliver, M. (1990): The Politics of Disablement, Londres: Macmillan.

Oliver, M. (I986): "Social policy and disability: some theoretical issues", Disability, Handicap and Society, I(I): 5-I7. 
Organización Mundial de la Salud (OMS) (200I): Clasificación Internacional de Funcionamiento, de la Discapacidad y de la Salud, Madrid: Ministerio de Trabajo y Asuntos Sociales, Instituto de Migraciones y Servicios Sociales (IMSERSO).

Palacios A. y Romañach J. (2006): El Modelo de la Diversidad. La Bioética y los Derechos Humanos como herramienta para alcanzar la plena dignidad en la Diversidad Funcional, Santiago de Compostela: Diversitas.

Palacios, A. (2008): El modelo social de la discapacidad: orígenes, caracterización y plasmación en la Convención Internacional sobre los Derechos de las Personas con Discapacidad, Madrid: Cinca.

Pantano, L. (2009): "Nuevas miradas en relación con la conceptualización de la discapacidad. Condición y situación de discapacidad". En: Brogna, P. y Sánchez Ventura, M. (comp.): Visiones y revisiones de la discapacidad, México: FCE.

Payne, M. (I995): Teorías contemporáneas del Trabajo Social. Una introducción crítica, Barcelona: Paidós.

Pfeilstetter, R. (2010): "Lo normal puesto en escena”, La Gazeta de Antropología, 26(I).

Platero M., R. L. y Rosón, V. M. (20I2): “De la 'parada de los monstruos' a los monstruos de lo cotidiano: la diversidad funcional y la sexualidad no normativa", Feminismo/s: revista del Centro de Estudios sobre la Mujer de la Universidad de Alicante, I9: I27-I42.

Preciado, B. (20I3): “¿La muerte de la clínica?” Conferencia impartida en el Museo Nacional Centro de Arte Reina Sofía, 9/3/2013, Madrid (paper).

Preiswerk, R. y Perrot, D. (I979): Etnocentrismo e historia:(América indígena, Africa y Asia en la visión distorsionada de la cultura occidental), México: Nueva Imagen.

Puig de la Bellacasa, R. (I990): Concepciones, paradigmas y evolución de sobre la discapacidad, Madrid: Real Patronato de Prevención y Atención a Personas con Minusvalía.
Riddel, S. (I998): “Teorizar sobre las necesidades educativas especiales en un clima político cambiante". En: Barton L. (comp.): Discapacidad y Sociedad, Madrid: Morata: 99-I23.

Rius, I. (20I2) "La imagen de los Juegos en la prensa" En: Solves, J. (coord.): Tratamiento de los Juegos Paralímpicos de 2008 en los medios españoles, Madrid: Cinca Ediciones, Colección CERMI: 89-I 58 .

Rodríguez Díaz, S. (20I3): “Más allá de la discapacidad: reflexiones en torno a la relatividad de la organización sensorial", Revista Española de Discapacidad, I(2): 5I-58.

Rodríguez Díaz, S. y Ferreira, M. A. (2010a): "Desde la dis-capacidad hacia la diversidad funcional. Un ejercicio de dis-normalización”, Revista Internacional de Sociología, 68(2): 289309.

Rodríguez Díaz, S. y Ferreira, M. A. V. (20 Iob): "Diversidad funcional: Sobre lo normal y lo patológico en torno a la condición social de la dis-capacidad", Cuadernos de Relaciones Laborales, 28(I): I 5I-I72.

Rodríguez Prieto, R. y Seco, J. M. M. (2007): "Hegemonía y democracia en el siglo XXI: ¿Por qué Gramsci?”, Cuadernos electrónicos de filosofía del derecho, 5: I 2.

Rosato, A. et al. (2009): "El papel de la ideología de la normalidad en la producción de discapacidad", Ciencia, docencia y tecnología, (39): 87-I05.

Rosato, A. y Angelino, M. A. (2009): Discapacidad e ideología de la normalidad, Buenos Aires: Noveduc Libros.

Salazar, F. (2005): "La configuración del Estado de Bienestar: Elementos constitutivos”, Reflexión Política, 7(I4): I 26-I 40.

Sánchez De Amo, A. y Marqués, S., (2003): Cómo mejorar la comunicación social sobre discapacidad, Madrid: Real Patronato sobre Discapacidad, Ministerio de Trabajo y Asuntos Sociales.

Scheerenberger, R. C. (1984): Historia del retraso mental, Donostia-San Sebastián, SIIS Centro de Documentación y Estudios. 
Sennett, R. (20I I): El declive del hombre público, Barcelona: Anagrama.

Shakespeare, T. \& Watson. N. (I995): "Habemus Corpus. Sociology of the body and the issue of impairment", $5^{a}$ Conferencia de Historia de la Medicina, Aberdeen.

Shakespeare, T. (I996): "Rules of engagement: doing disability search", Disability and Society, II: I I 5-I 20 .

Shakespeare, T. (I994): "Cultural representations of disabled people: dustbins for disavowal", Disability and Society, 9(3):283-30I.

Shapiro, J. (1994): No Pity: People with Disabilities Forging a New Civil Rights Movement, New York: Times Books, Random House.

Simon, B. (I984): Razón y locura en la antigua Grecia, Madrid: Akal.

Soder, M. (I989): "Disability as a social construct: the labelling approache visited", European Journal of Special Needs Education, 4(2): I I7I29.

Solves Almela, J. (Coord.) (2OI 2): Tratamiento de los Juegos Paralímpicos de 2008 en los medios españoles, Madrid: CERMI.

Sossa Rojas, A. (20II): “Análisis desde Michael Foucault referentes al cuerpo, la belleza física y el consumo", Polis, Revista de la Universidad Bolivariana, Iо(28): 559-58I.

Sumalla, E. C. et al. (2013): “¿Por qué las mujeres con cáncer de mama deben estar guapas y los hombres con cáncer de próstata pueden ir sin afeitar? Oncología, Disidencia y Cultura Hegemónica”, Psicooncología, I(10): 7-56.
Thomas, D. (1982): The Experience of Handicap, Londres: Methuen.

Toboso Martín, M. y Guzmán Castillo, F. (20I0) "Cuerpos, capacidades, exigencias funcionales y otros lechos de procusto", Política y Sociedad, $47(\mathrm{I}): 67-83$.

Tooley, M. (I983): Abortion and Infaticide, Nueva York. Oxford University Press.

Vain, P y Rosato, A. (Coord.) (2005): La construcción social de la normalidad: Alteridades, diferencias y diversidad. Ensayos y Experiencias, Buenos Aires: Noveduc.

Vásquez Rocca, A. (2008): "Zygmunt Bauman; Modernidad Líquida y Fragilidad Humana”, Observaciones filosóficas, I3 (6).

Warnock, H. M. (I978): “Special Educational Needs. Report of the Committee of Enquiry into the Education of the Handicapped Children and Young People”, Londres: HMSO.

Werneck, C. (2005): Manual sobre Desarrollo Inclusivo para los Medios y Profesionales de la Comunicación, Brasil: WVA.

Yates, L. (I993): "Feminism and Australian State Policy: Some Questions fot he I990s"”. En: Arnot, M. \& Weiler, K.: Feminism and Social Justice in Education: International Perspectives, Londres: Falmer Press.

Žižek, S. (I998): "Multiculturalismo o la lógica cultural del capitalismo multinacional”. En: Fredric, J. \& Slavoj, Z.: Estudios Culturales. Reflexiones sobre el multiculturalismo, Buenos Aires: Paidós. 